\title{
Chapter 14 \\ Possibilities of Social Bonds Using to Finance Higher Education Institutions
}

\author{
Natalia Konovalova
}

\begin{abstract}
In many countries, funding for higher education institutions is insufficient and requires the search for new financial instruments and financing models. One such financing model could be the issuance of social impact bonds aimed at improving the efficiency of higher education institutions. The study focuses on the use of financial instruments as social bonds for additional funding of higher education institutions. The peculiarities of social bonds and the possibilities of their application in the field of higher education are explored in the paper. The results of the study comprise three proposed innovative approaches to the development of a mechanism for the issuance of bonds. The first approach assumes that the issuer of social bonds in favour of the university is a bank or other financial institution. The second approach is based on the methodology of issuing social bonds by a university with the participation of the state. The third approach to the use of social bonds is the creation of a platform for financing long-term educational programs; it can be done with the participation of a large company implementing large-scale socio-economic projects. Such platform will have a great social and economic effect.
\end{abstract}

Keywords Higher education institutions · Social impact bonds · Investors ·

Extrabudgetary financing $\cdot$ Flowchart

\section{Key Points of the Chapter Are the Following}

- Higher education efficiency can be improved through a combination of budgetary and extrabudgetary sources of funding.

- The sources of off-budget financing of universities can be expanded through various social and charitable programs, as well as through the issue of social impact bonds.

\footnotetext{
N. Konovalova $(\bowtie)$

RISEBA University of Applied Sciences, Riga, Latvia

e-mail: natalija.konovalova@riseba.lv

C. Păunescu et al. (eds.), Social Innovation in Higher Education, Innovation,

Technology, and Knowledge Management,

https://doi.org/10.1007/978-3-030-84044-0_14
} 
- One of the most effective way to finance universities is through the issuance of municipal social bonds.

- In order to accelerate the implementation of universities' social impact bonds in Latvia, it is necessary to launch a pilot project at the municipal level.

- The chapter introduces the flowcharts of issuance of social bonds by universities with various options of interaction of the project participants.

\section{Introduction}

As is known, higher education includes a set of systematized knowledge and practical skills, which allow to solve theoretical and practical problems on a professional profile, using and creatively developing modern achievements of science, technology and culture. Consequently, higher education aims to ensure that graduates of higher schools, by realizing their acquired knowledge in the process of working life, benefit society and the state as a whole, ensuring its constant development. It is obvious that higher education has not only an educational and scientific dimension, but also solves the social problems of society. In most European countries, higher education institutions are funding based on public and private capital. However, the proportion of private and public funding in higher education varies from country to country. Besides, the tendency of public financing for universities is decreased in many countries (Eurostat, 2020). What supplementary finance sources can be used in the education system? The article argues that the sources of off-budget financing of universities can be expanded through various social and charitable programs, as well as through the issue of social bonds.

The use of social bonds is always associated with a certain impact on the project being implemented. Therefore, the term "social bonds" and the term "social impact bonds" are interchangeable. Social bonds are one of the dynamic innovative instruments for financing social projects through public and private partnerships. Social impact bonds are debt securities that contains a loan agreement based on mutually beneficial conditions of interaction between several organizations of different profiles of activity but striving to achieve a certain socially significant result (Burand, 2013). In its simple original form, social impact bonds are a bond loan of the bank, which is aimed at attracting charitable funds. The money that will be received during this loan should be used to finance large projects of the university with the participation of the state or to implement a certain educational program, which is carried out by a non-profit organization. Social impact bonds are issued in favour of another person but have certain conditions. So, if the project financed in this way is successfully implemented, then the costs are compensated by the state. But if the results are not achieved, then a refund will not be provided. Therefore, social impact bonds are called "pay for success". Thus, the participants in such an investment product are the state, social facilities, banks, non-profit organizations, investors, social auditors, investment consultants. The effectiveness of investments and the achievement of goals by all participants in the investment program depend on a 
coherent interaction. Interest in this instrument is growing rapidly, owing to its potential to attract long-term investment in the development of a resource base for social projects (Choudhary \& Jain, 2017). It seems that efficiency in higher education can be enhanced through a combination of budget and off-budget sources of funding.

One of the main participants in a social project using social impact bonds may be higher education institutions, since they are a sphere aimed ultimately at creating social benefits. And it is the process of education at a university that represents the primary stage of creating a social good-the formation of an educated intelligent person with special knowledge and skills, who can later independently create other social benefits in society. Therefore, universities and other higher education institutions contribute to creation and formation of the individuals who will be beneficial to society due to implementation of the acquired base of knowledge and skills. And this is an important social project and an important type of social entrepreneurship. Therefore, social impact bonds of universities can become an extrabudgetary tool and a source of funding for higher education institutions. Since educational and socio-economic goals can be realized simultaneously, thanks to the interaction of universities with research centres, research laboratories, business incubators and other business organizations, the application of social bonds can be successfully used to finance higher education institutions.

The aim of the study is a development of a mechanism of issuance of social bonds by universities with various options of interaction of the project participants; it will be done based on an analysis of the financial needs of universities, an assessment of their social impact and possibilities of obtaining off-budget financing. The object of the study is higher education institutions of Latvia. Methodology employed relies on observation, survey, interviews, economic analysis and synthesis. The survey was conducted among academic staff in Latvian higher education institutions to determine the level of efficiency of social impact bonds use. The interview was conducted with heads of Latvian commercial banks and with heads of large Latvian companies to reveal the degree of readiness of investors to be partners for universities. The theoretical and methodological basis of the study are the normative documents and legislative acts of Latvia and directives of the European Union, scientific and special literature on the problem under study, scientific articles and periodicals.

\section{Background and Theoretical Framework of Social Investment through Impact Bonds}

In modern economic studies, it is common knowledge that the liberalization of economic relations is characterized by a decrease in the contribution of the state to solving social problems. This is due to both the lack of resources in the state and the content of the liberal worldview of its leadership. In turn, this requires the creation of institutional conditions for the development of various forms of social investment 
with the participation of private capital. Social investment has become the dominant approach to welfare reform in Europe and elsewhere (Jackson, 2013). Scholars supporting this perspective have argued that it represents a paradigm shift from neo-liberalism-defined as the ideology of the minimal state and welfare retrenchment (Laruffa, 2018).

The development of social investment is a consequence of the evolution of liberalism, according to which individual interests with full freedom will not always benefit the public interest (Ives, 2015). The article debates that it is not entirely correct to argue that granting freedom for individual interests will automatically improve the satisfaction of public interests. Most famous economists in world science agreed that it is necessary to use state regulatory and management mechanisms to solve public problems, since "clean" competition in the market and the desire to maximize profits alone are not able to do this on their own Burand, 2013).

One type of impact investing is the social impact bond (SIB), an arrangement where investors in a project receive financial returns based on the project outcomes, specifically the accomplishment of prespecified social objectives. Social impact bonds are geared toward funding social interventions while earning financial returns (Marco, 2018). Broccardo and Mazzuca claim that SIBs can provide a functional linking mechanism in social service systems. Furthermore, they can help boost the innovation and sustainability of this system (Broccardo \& Mazzuca, 2019). Social impact bonds have been welcomed enthusiastically as a new funding tool for social innovation, yet also condemned as an instrument that neglects beneficiaries' and taxpayers' interests, opening profit opportunities in the field of social politics for smart private investors (Maier Maier \& Meyer, 2017).

SIBs are financial instruments in which investor funds working capital for non-profit organizations that deliver a way to connect social sector with capital markets (Mulgan et al., 2011). If the non-profit organizations meet predefined objectives, public sector savings are realized, and the government then pays back the investors their principal plus a rate of return. However, if the savings are not realized, the investors get no repayment. In terms of investment risk, these instruments are more like an equity investment than a typical bond purchase. The most peculiar feature of these bonds is that they are based on result, and it is easy to register them in accountancy; another point is that the government reimburses the amount only when the desired social objective is achieved, otherwise no payment is made. SIBs are more systematic and analytical since they are based on proper identification and assessment of a social problem whose solution is to be sought. Since careful analysis and assessment of social problem is done before investing the amount, there are less chances of failure as more result-oriented targets are achieved (Choudhary \& Jain, 2017). Social impact bonds attract private investment to social programs by paying a market rate of return if predefined outcome targets are met. SIBs monetize benefits of social interventions and tie pay to performance, limiting governmental control once the contract is designed. Despite policy enthusiasm across the globe, SIBs have failed to attract private market investors without substantial additional guarantees. SIBs raise questions about government's ability to ensure broader public values (Warner, 2013). Social impact bonds combine some 
components of results or performance, based on financing and public-private partnerships, which have been used to fund public services for many decades (Burand, 2013).

However, impact bonds differ in several ways. First, in an impact bond, financing is provided upfront rather than when results are attained. Second, results in social impact bonds are usually related to outcomes as opposed to outputs. Third, impact bonds can focus on the delivery of human services as opposed to the traditional physical infrastructure that has often been the center of both public-private partnerships and performance contracts. Finally, in contrast to programs such as Program for Results (P4R) or results-based financing (RBF) being used by the World Bank, impact bonds bring in private sector rigor and performance management to drive results. The prototype of social bonds can be considered a non-tradable version of social policy bonds (SPB), developed by Horesh in the paper "Injecting incentives into the solution of social problems: Social policy bonds.", which described a new type of investment (Horesh, 2008). This type of bond can be issued by the local government or the government of the country and sold at auction to the person who offered the highest price. After issue, the bonds will be freely circulating. Social policy bonds are interest-free, with an indefinite maturity date. The state guarantees the redemption of bonds for a fixed value only if the social goal is achieved. Therefore, they can help solve any problems in society that need to be reliably defined and quantified. The peculiarity of social bonds is that they do not bring financial benefits during their circulation but bring income after project implementation only. An investor can make a profit only depending on the result of the investment, otherwise they lose the invested funds. Therefore, in terms of risk, social bonds are more like equity investments or a structured product.

The idea of social bonds was developed in the UK, where since 2007 a special council under the Prime Minister has been developing various alternative financing tools for solving social problems (Eddy, 2015). The term "social impact bond" was introduced by Mulgan, and the first issue was authorized by the UK Department of Justice in 2010 (Mulgan et al., 2011). Currently, the development of this tool is actively engaged in the American company Social Finance US, which considers social bonds as an instrument of public-private partnership, which finances effective social services through a conditional contract aimed at obtaining a certain social result (Dear et al., 2016). Development Impact Bond (DIB) is a modification of social bonds in many developed countries (Burand, 2013). DIBs are specially adapted to the social problems of developing countries. Their main difference from social bonds is that a large international organization is usually the payer for the result of investment. Investors are either organizations from another country or from the country where the investment is made. In turn, the state, represented by the government of the country in whose territory social investment is carried out, acts as a coordinator and helps to select independent evaluators to assess the social impact of the project and local performers, and can also be one of the parties to this transaction. Thus, development bonds in their institutional form are similar to social bonds, but the main goal for them is the socio-economic development of the territory as a whole (Eddy, 2015). 
It should be noted that social bonds as financial instruments have their disadvantages and advantages. Proponents of this financing tool emphasize the possibility of using them not only for socially oriented, but also for innovative projects in the early stages of development through attracting private funds and private investors, encouraged by the state through the provision of tax benefits until positive results are obtained for the project (Burand, 2013). The expected savings of the state budget are used as a basis for attracting investment in the implementation of programs for prevention and early intervention in solving socially significant problems that will prevent their development in the future. Critics of this financing tool note that since the state pays investors income when reaching the result from the previously planned budget for social projects, it turns out that social bonds do not attract additional capital to solve social problems, but instead, on the contrary, divert part of the money intended to finance other projects (Horesh, 2008). In addition, the implementation of the project through social bonds can be much more expensive for the state compared to other ways of financing due to the fact that it is necessary to hire specialists who know the mechanisms for implementing the project and independent evaluators to determine the effectiveness in achieving the intended goals. Social impact bond is one of the dynamically developing innovative tools for financing social projects based on public and private partnerships. SIB is a debt liability (security) that contains a loan agreement based on mutually beneficial conditions of interaction between several organizations of different profiles of activity but striving to achieve a certain socially significant result.

\section{Social Impact Bonds Feasibility Criteria}

Four basic criteria are necessary for impact bonds to come to fruition. These criteria are "meaningful and measurable outcomes", "reasonable time horizon to achieve outcomes", "evidence of success in achieving outcomes", "appropriate legal and political conditions" (Eddy, 2015). Meaningful outcomes should minimally be indicative of outcomes that are predictive of the life trajectory of an individual. If an outcome has no evidence that demonstrates that it will lead to better outcomes later on, paying for it doesn't make a great deal of sense. While interventions should by no means be limited to the outcomes that are interesting to outcomes funders, when choosing outcomes for repayment in social impact bonds (SIB), ultimately the outcome must be attractive to them. This likely means that the outcome metric should be a meaningful proxy for longer-term economic outcomes (GustafssonWright et al. 2015a, b).

Reasonable time horizon to achieve outcomes is a second criteria of social impact bonds feasibility. A time horizon for achieving outcomes is reasonable if there is substantial evidence from previous evaluations that the specified outcomes will occur within this time frame. At the same time, a reasonable time horizon is one in which outcomes are measurable and therefore indicative of future life-long opportunities for the individuals. A reasonable time horizon will also be one in which 
investors and outcome funders are able and willing to make and receive payments given, for instance, legal and political conditions in a country.

The third criterion of social impact bonds feasibility is evidence of success in achieving outcomes. Evidence of success in achieving outcomes should come from evaluations of interventions that closely mirror the services and how they are delivered in an intervention supported by an impact bond. These evaluations are best if they come from a context similar to the one in which an impact bond is planned, though this is not absolutely necessary. At the very least, evidence should probably be available at the country level for an impact bond to be considered feasible (Gustafsson-Wright et al. 2015a, b). Rigorous evaluations are recommended, such as randomized control trials or other techniques that compare outcomes for a group receiving a service with another group that does not receive a service, while also accounting for differences between the groups compared. Ultimately, however, the extent to which evidence must be rigorous is very dependent on the risk appetite of the investors and the requirements of outcome funders.

One more criterion of social impact bonds feasibility is appropriate legal and political conditions. Appropriate political conditions are those that demonstrate support for the services delivered in an impact bond by relevant stakeholders, including local, state, and national governments, as well as investors. Support for a particular service may be found in a policy framework or strategy document or may be demonstrated in previous funding allocated to services. In addition, appropriate legal conditions will enable governments (in their role as outcome funders) to pay for outcomes beyond the fiscal year in which a contract is made and for that matter to pay for outcomes at all. This is often necessary since most public expenditure is committed on a yearly basis. It may also be necessary for legal conditions to support the ability of the government to direct funds to an intermediary in a transaction and for the intermediary to have the authority to make certain decisions, such as selecting a service provider. Legal conditions will also facilitate a transaction such that investors have contract protections and are incentivized to provide capital for the impact bond (Stump \& Johnson, 2016). Other relevant issues that may influence the feasibility of an impact bond include how governments treat hybrid investments, which include debt and equity components, and how they treat various stakeholders involved in a deal that may be located outside of a country.

The design of an impact bond can vary greatly in terms of the composition of the players involved, their roles, and the timeline and process of putting. The development process for an impact bond transaction is unique to each deal, though four major stages of the process are fairly consistent across deals: a feasibility study, structuring the deal, implementation, and evaluation and repayment (Acevedo \& Live, 2016). Within those stages, there are some basic components of each deal process. These include the identification of a social challenge; an assessment of feasibility for developing an impact bond based on a set of criteria; the raising of capital from senior and/or subordinate lenders or grant makers; the defining of the intervention, outcomes metrics, and evaluation methodology; the procurement of a service provider (which can occur through various different processes); the negotiation of contracts between stakeholders; the provision of the services; performance 
management (in some cases); and evaluation. The order in which these components take place can vary greatly across deals (Gustafsson-Wright et al. 2015a, b).

For example, in some cases a service provider is identified early on in the process, allowing inclusion of service provider-specific data in the feasibility analysis; in other cases, the service provider is procured after the identification of an intervention and after a feasibility analysis are conducted. Similarly, the capital can be raised before or after securing an outcome funder depending on the circumstances. Social impact bonds can be fully used to finance higher education institutions. Higher education financing must compete with an array of other public service. A new type of public-private relationship is needed, but such a relationship must do more than simply share accountability - it must also alleviate fiscal pressures on students and their families and create mechanisms that prevent more tuition increases (Salerno, 2016). Salerno in the paper "Higher Education: social impact bonds and income share agreements" concludes that most agree on the unrealistic expectation of continued growth of public investment in higher education or the funnelling of more funds into existing investment vehicles (Salerno, 2016). SIBs and individual savings accounts (ISA) represent novel solutions to limited government budgets. They promote accountability and long-term investment in educational infrastructure. They align risk and reward. They are both flexible and responsive to changing labour market dynamics. Making these tools work will require new ways of thinking about not just public priorities but also private-sector investment risk and reward (Salerno, 2016). Social Impact Bonds are a relatively new funding mechanism of social projects. In education, there are thirteen SIBs underway around the world related to vocational education and early childhood education (Bloomgarden et al., 2014). But Social Impact Bonds have a big potential of development. Evidently Social Impact Bonds are a novel financing mechanism for public services delivery. SIBs are a strategically ambiguous policy tool and policymakers should be cautious about SIBs due to contractual complexity and issues with ethics, governance, accountability and transparency (Tan et al., 2019).

\section{Opportunities for Using Sources of Funding Based on Public-Private Partnerships in Latvian Higher Education}

The proportion of public and private funding for higher education varies from country to country. Public funding in higher education costs is about $90 \%$ in Austria and Italy, about $80 \%$ in Portugal and Finland, about 2/3 in the UK, Denmark, Sweden, Ireland (OECD, 2020). Most German universities are state-owned, and tuition is free of charge. At the same time, more than $30 \%$ of students receive material assistance either from the federal budget (33\% of all funds), or from land budgets (45\%), or from various communities (22\%) (Kottmann et al., 2019). However, in many other countries, public funding for universities is less than $50 \%$. And 


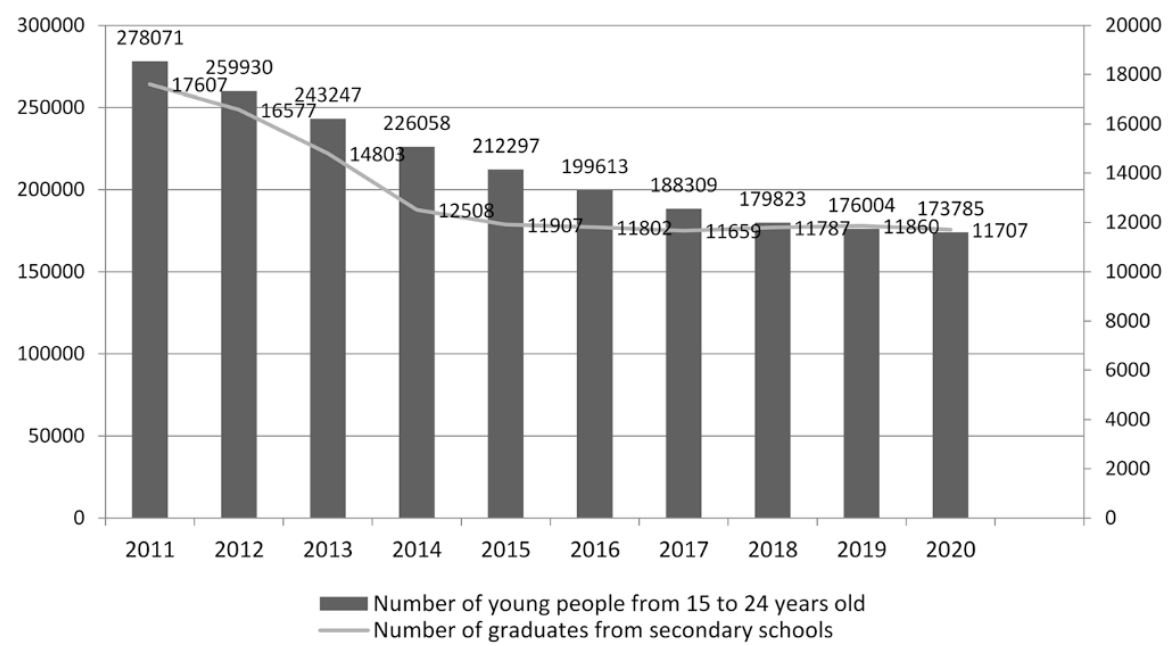

Fig. 14.1 Number of young people from 15 to 24 years old and number of graduates from secondary schools in Latvia (Source: Latvian Ministry of Education and Science, 2021)

universities are forced to look for additional sources of funding. In Latvia, state financing of universities is less than $40 \%$ and has a large differentiation in the fields of education. It should be noted that the total number of students in Latvia is decreasing, which is associated with a decrease in the number of secondary school graduates and the number of young people from 15 to 24 years old (Fig. 14.1). The data of the Central Statistical Bureau of Latvia evidences that 78,500 students are studying at Latvian universities in the 2020/2021 academic year (Central Statistical Bureau of Latvia, 2021). It is $1.1 \%$ less than a year ago. The number of newly enrolled students also decreased. In the 2020/2021 academic year, 28,700 students entered universities in Latvia, which is $2.4 \%$ less than a year earlier. Half of the newly enrolled students (51.6\%) in the 2020/2021 academic year began undergraduate studies, $24.8 \%$ began master's programs, $21.7 \%$ began college programs and $1.9 \%$ began doctoral programs.

More than half of students $(56.1 \%)$ in the 2020/2021 academic year began their studies at their own expense, and 43.9\% — at the expense of the state budget. A more significant difference between extra-budgetary students and budgetary students is observed in the total number of students studying at Latvian universities. So, in the $2020 / 2021$ academic year, the share of students studying at their own expense is $61 \%$, and the share of students studying at the expense of the state budget is $39 \%$ (Fig. 14.2).

When analysing the dynamic of the total number of students and the proportion of budgetary and extra-budgetary students in Latvia over the past 20 years, it can be seen that the largest number of students in Latvia was recorded in the period from $2003 / 2004$ to $2008 / 2009$ academic years, and the share of students studying at the expense of the state budget during this period fluctuated within 23-26\%. This means that the bulk of students received higher education at their own expense (74-77\%). 


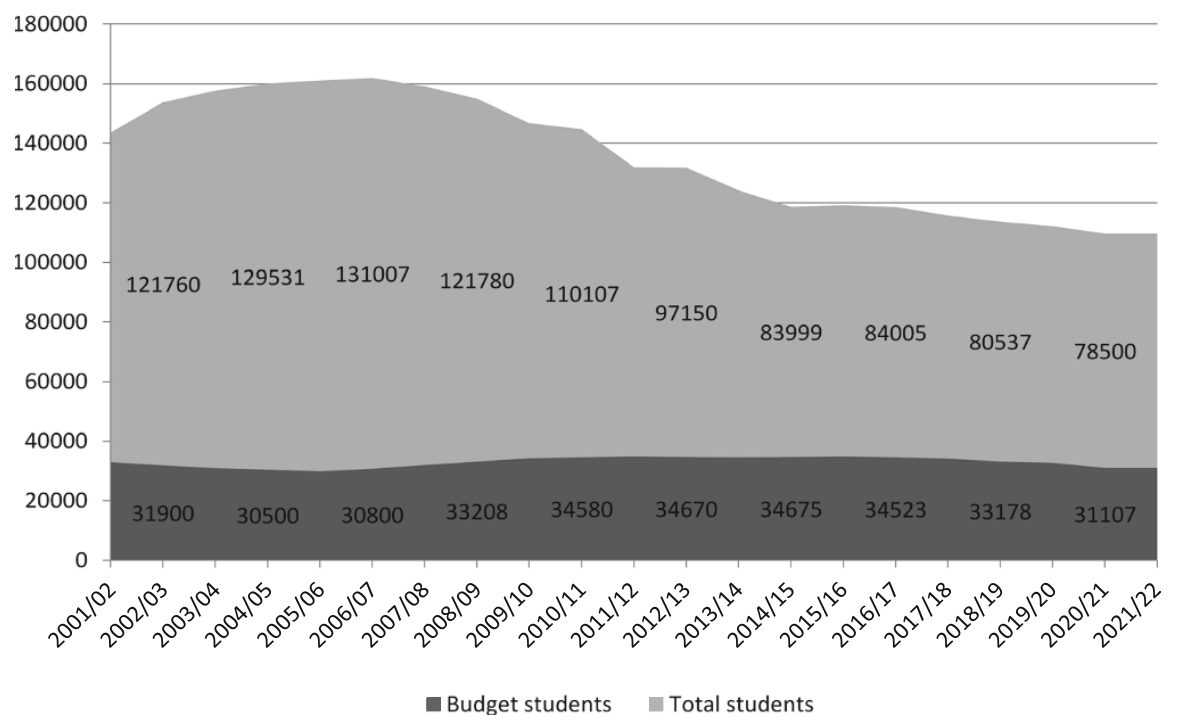

Fig. 14.2 Quantity of students in Latvia (Source: Latvian Ministry of Education and Science, 2021)

Figure 14.2 also shows that in subsequent years, the share of students studying at their own expense is decreasing, and the share of students studying at the expense of the state budget is slightly increasing. But this is not due to an increase in state funding, but to a decrease in the total number of students. And as shown in Fig. 14.2, the number of students studying on the budget in the last eight years also has a certain tendency to decrease. It should be noted that the proportion of public and private financing in Latvia has a large differentiation in the fields of education. Thus, the Fig. 14.3 shows that the priority areas of state financing are engineering sciences, natural sciences, humanities, health care and agriculture. These areas are financed by the state to the greatest extent (over 50\%). More than half of students studying in the above-mentioned areas study at the state budget expense. At the same time, studying in social sciences, education and services is funded by the state in a minimum amount. Such educational areas as education and service are financed from the state budget less than $40 \%$. The lowest funding from the state budget is allocated for social sciences. In the 2010/2011 academic year the share of budget financing for social sciences amounted $11 \%$, in 2020/2021 it was $15 \%$. This means that students in these areas study mainly at their own expense.

All these facts show that Latvian higher education institutions face the problem of lack of funding, which requires the search for new solutions. It is assumed this problem can be solved by issuing of social impact bonds.

The research presents the conducted a survey of academic staff in Latvian higher education institutions (the sample was $20 \%$ or 1100 respondents), as well as conducted interviews with potential investors and representatives of state authorities (mainly with experts from the Ministry of Education and Science of Latvia). 


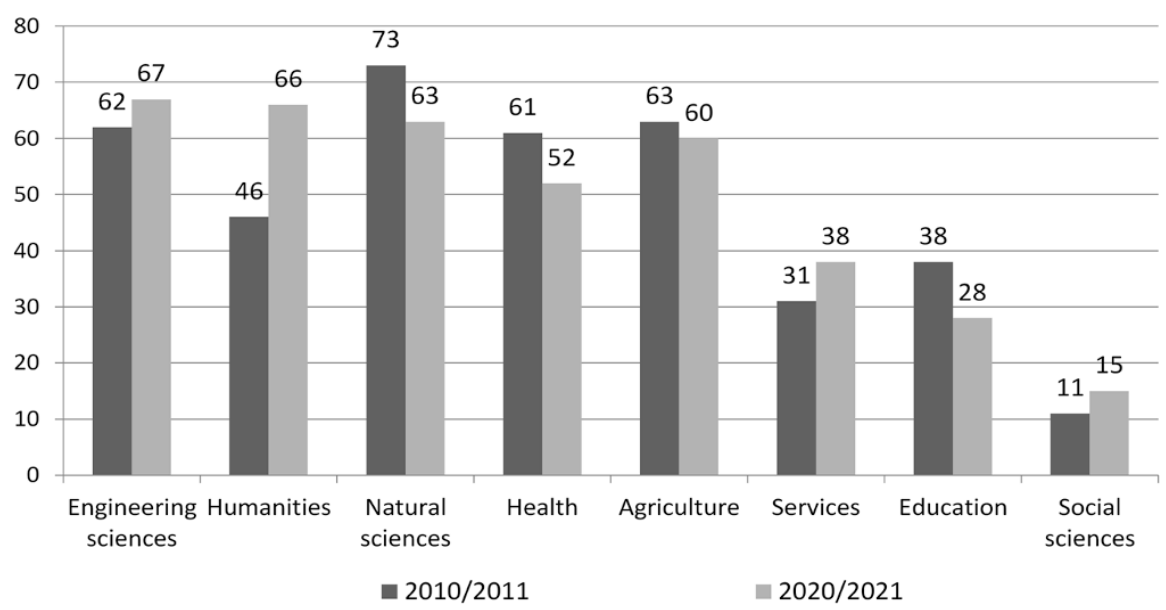

Fig. 14.3 Percentage of students in Latvia studying at the expense of budget funds in areas of study /thematic groups/ (Source: Latvian Ministry of Education and Science, 2021)

According to the results of a survey of Latvian academic staff, conclusions were made about the technical condition of universities, about trends in the number of students, the ratio of public and private funding of Latvian universities, as well as about the level of efficiency of various types of financing. The results of the survey of academic staff showed that the average assessment of the technical condition of Latvian universities on a 5-point scale is estimated at 3.8. In addition, academic staff noted that in the future in Latvia the number of students would decrease, and tuition fees would increase. At the same time, tuition fees would not be an important component of the universities' budget.

In state universities tuition fees in average would be $20 \%$ of the total budget of universities; in private universities the share of tuition fees would be at the level $60-65 \%$ of the total private universities' budget. At the same time, respondents noted that the negative point was that in average only $60 \%$ of the total number of enrolled students completed their studies. The Latvian academic staff noted that most negative factor was that in the future Latvian universities will be forced to work "idling" and quantitative indicators would dominate over qualitative. As for the opinion of respondents on the effectiveness of funding sources for universities, the Latvian academic staff noted that the most effective source of funding for universities is direct municipal funding $(39.8 \%$ of respondents indicated the highest efficiency level of this source). The possibility of financing universities through social impact bonds was evaluated by academic staff relatively high. $35.2 \%$ of respondents noted a high level of efficiency from the use of social impact bonds, $31.1 \%$ of respondents noted an average level of efficiency of this source, and only $14 \%$ considered that the efficiency of this source considered low. Summary processed survey results of the funding efficiency level of higher education institutions are shown in Table 14.1. The results of interviews with potential investors highlighted the problems and made it possible to determine the degree of readiness of investors 
Table 14.1 Survey results of Latvian higher education institutions' academic personal /as a percentage of total number of responses/

\begin{tabular}{l|l|l|l}
\hline & \multicolumn{3}{|l}{$\begin{array}{l}\text { Level of funding efficiency in } \\
\text { higher education institutions } \\
\text { (1 - high level, 2 - average } \\
\text { level, 3 - low level) }\end{array}$} \\
\cline { 2 - 4 } Funding type & 1 & 2 & 3 \\
\hline Direct state budget funding & $31.1 \%$ & $22.8 \%$ & $23.3 \%$ \\
\hline Direct municipal funding & $39.8 \%$ & $19.3 \%$ & $18.3 \%$ \\
\hline Bank loans & $21.1 \%$ & $38.3 \%$ & $13.3 \%$ \\
\hline Funding with social impact bonds (SIB) & $35.2 \%$ & $31.1 \%$ & $14.4 \%$ \\
\hline Other extrabudgetary sources of funding (sponsorship etc.) & $12.4 \%$ & $33.2 \%$ & $41.1 \%$ \\
\hline Son & &
\end{tabular}

Source: developed by author based on the survey of Latvian universities' academic staff

to be partners for universities. As it turned out, for the work of social impact bond system, the presence of an enough investors number who would be ready to participate in the initial financing and agreement with the government is necessary. In order to find out the attitude of investors to the possibilities of social investment, the author conducted interviews with the heads of three Latvian commercial banks and the heads of two large Latvian companies. The results of interviews with heads of commercial banks showed that the possibility of the bank's participation in financing of university using social impact bonds depends on the bank's investment strategy. However, all participants in the interview agreed with the prospects of such projects and pointed out their high effectiveness and benefits for society. However, they noted that investment should be attractive and the return on investment should be $10-15 \%$.

The same opinion on the return on investment in projects associated with universities was expressed by the heads of large Latvian companies. They believed that the return on investment at $15 \%$ was not great, but it was stable in the long-term period. At the same time, all interviewees during the implementation of projects would be interested in obtaining good specialists from the circle of university graduates.

The question about return on investment was also asked to experts from the Ministry of Education and Science of Latvia. Experts of the Ministry of Education and Science believe that the commercial return on the implementation of such projects can be even $0 \%$, but the utility effect in society will be much higher. But to ensure attractiveness to investors, the return on educational projects using social impact bonds can be no higher than 5\%. According to the representative of the Ministry of Education and Science, too much return may not be understood by investors and may even be an obstacle to attracting investment; given the Latvian mentality, it will most likely be associated with unreliability, shadow transactions and schemes. According to the author, the return on social investment projects of universities should be at the level between the long-term yield of Latvian government bonds and the yield offered in the equity markets. However, with low equity 
yields, it may be higher than long-term government bond yields and equity market yields.

As a result of the interview, it was revealed that many investors pay great attention to their reputation assessment. And this is one of the important reasons for social investment. But the factor stopping the investor from investing money is the unknown and insufficient understanding of the investment scheme. Investors note that it is very important for them to fully understand the mechanism and functions of all parties involved in the project, as well as the risks associated with the implementation of the project. The interview studied the issues about the readiness of Latvia for using the social impact bonds to finance universities, the degree of feasibility of this process for the country, the obstacles for the implementation of the projects concerning the social impact bonds. It was revealed that there are obstacles to the use of social impact bonds. The main obstacle may be resistance from the public sector, which is mainly due to the lack of experience in publicprivate partnerships. However, the situation is changing, and it is believed that it is moving in the direction of an environment that would be more favorable for the use of social impact bonds. This shift can be expected to be slow, as it also requires a change in mentality and attitudes. The changes can be faster if they are supported by appropriate educational programs and, possibly, the launch of a pilot project. The survey of academic staff revealed that the highest efficiency of universities financing could be ensured through the sources of direct municipal funding and the use of social impact bonds. Therefore, a successful pilot investment project could concern financing a university at the municipal level and be based on the interaction of the city municipality (representative of the authority), a large investor (represented by a commercial bank or a company) and a private university.

\section{Approaches to Social Impact Bonds Issue for Funding of Higher Education Institutions}

In order to attract additional sources to finance higher education institutions, at least three approaches can be used, which are based on the social impact bonds issue and the interaction of universities, governments (state), banks, private large companies and investors (Bloomgarden et al., 2014). The first approach is based on the social impact bonds issue by a bank in favour of the university. The second approach is based on social impact bonds with participation of a state as a guarantor and repayment of the bond debt depending on the implementation of the investment program. And the third approach is based on social impact bonds with the involvement of a private large company and a bank to finance long-term educational programs. Above mentioned approaches are suggested based on the study such literature sources as "The Potential and Limitations of Impact Bonds" written by Gustafsson-Wright, Gardiner, and Putcha, "Social Impact Bonds: An Innovative 


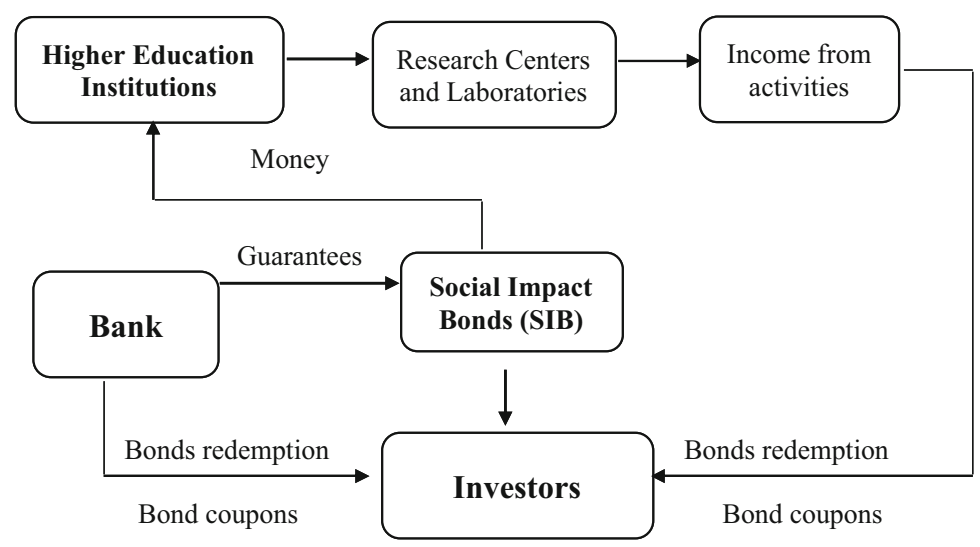

Fig. 14.4 Bonds issue by the bank in favour of the higher education institutions. Source: Author's contribution

Way for Social Financing" written by Choudhary and Jain, "Social Impact Bonds and Education in Latin America" written by Bloomgarden, Eddy and Levey.

How can banks issue social impact bonds in favour of the higher education institutions? When social impact bonds are issued by a bank in favour of the university, the bank also becomes a guarantor for the investor and undertakes to repay the bond debt and pay coupon income if the university cannot fulfil these obligations. In this case, the issue of investment (long-term credit) rating of bonds is resolved. A bank issuing bonds in favour of a university, as a rule, has a long-term credit rating, which means that the bond rating will be the same as the bank's rating. Therefore, these bonds become attractive and investors buy social impact bonds, which are issued by a bank in favour of the university.

This social impact bonds issue scheme is shown in Fig. 14.4. As can be seen from Fig. 14.4, higher education institutions create industry research centres and laboratories in which research and practice are conducted for students. Students there acquire skills, participate in experiments, generate ideas and embody them into practical activities. Thus, while still studying at a university, as well as after graduation, students applying their knowledge and ideas benefit society; they create public goods and produce added value. At the next stage, the result is income from activities in the workplaces of graduate students. And this added value is the source of repayment of the issued social impact bonds. This fact as well as efficiency analysis evidences that banks can issue social impact bonds with the purpose of financing the university. That is, the coverage of such bonds is material base of industry research centres and laboratories, and the source of their repayment will be the income from entrepreneurial activities in which graduates of the higher education institutions are involved.

The methodology of using the social impact bonds is based on an agreement between investors and a state on an implementation of sponsorship programs. The flowchart of the issuance of social impact bonds in accordance with this approach is 


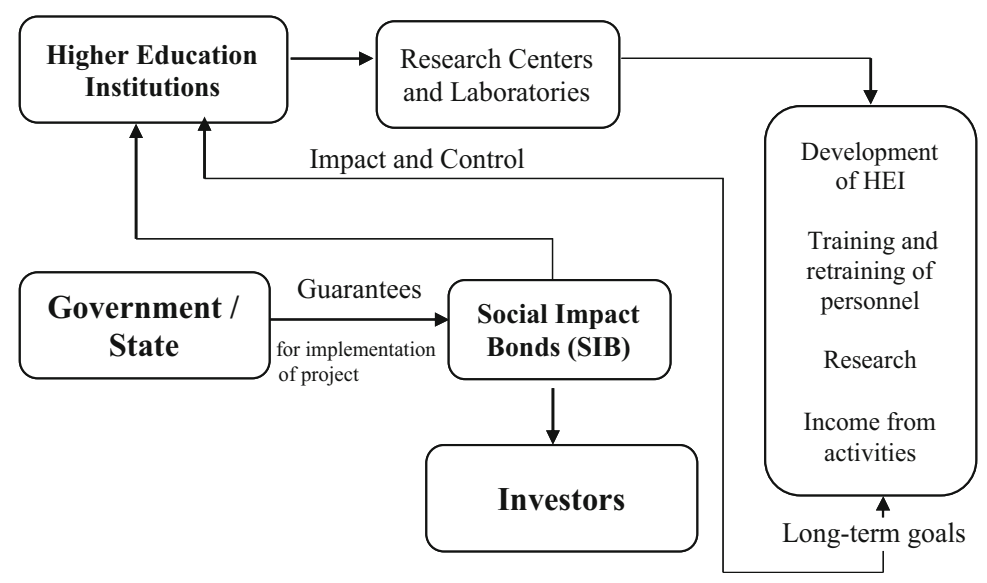

Fig. 14.5 Bonds issue with redemption depending on implementation of investment program Source: Author's contribution

shown in Fig. 14.5. Such projects proposed for funding are generally high-risk projects and require a strict control. The subject here is a direct investor who is interested in the success of the program and can ensure the return of invested funds. This approach makes repayment of the bond debt dependent on the effectiveness of the implemented investment program.

Financing by issuing bonds to projects such as research centers and laboratories that will be self-sustaining and can generate income from their entrepreneurial activities is promising. As a result, the efficiency of the use of state funds will increase, since the investor controls of project implementation and has long-term commercial goals. Thus, investors in social impact bonds can be industry organizations that are interested in research conducted by a higher education institution; organizations that are interested in long-term training and staff development programs; investment companies and banks that are interested in the successful development of an educational institutions and that implement social and sponsorship programs.

Finally, the third approach to the use of social impact bonds is the creation of SIB to finance long-term educational programs that can have a great social and economic effect without participation of a state. In this case, we can say that a large company implementing large-scale socio-economic projects will play the role of a state. An example of such an educational and at the same time socio-economic program can be a program for training entrepreneurs and creating small enterprises. This project of additional business education will result in the creation of new enterprises; consequently, there will be the social effect in the form of the creation of new jobs and services, provided to the society by newly created commercial organizations. The flowchart of social impact bonds issue according to the third approach is shown in Fig. 14.6. As can be seen from Fig. 14.6, higher education institutions develop and offer for training additional educational programs that can be implemented based on 


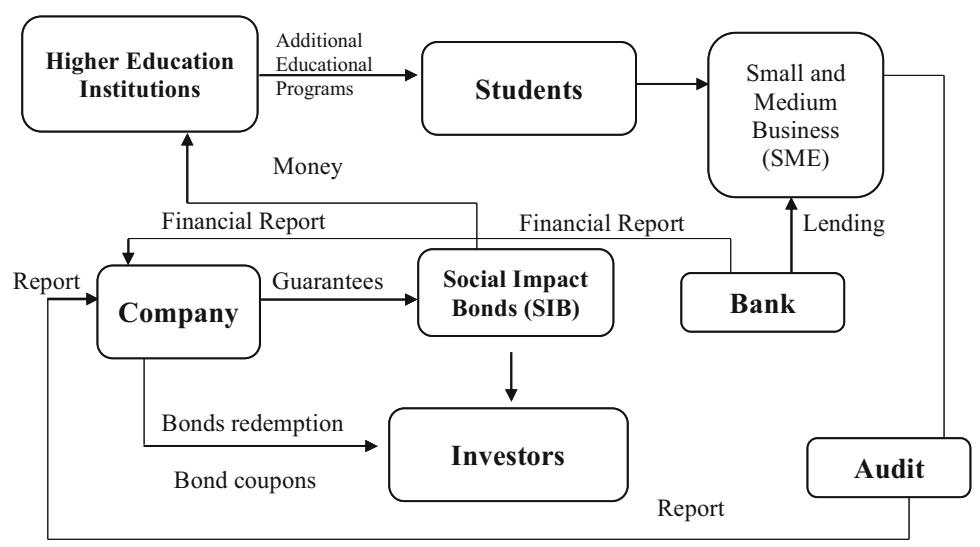

Fig. 14.6 Bonds issue for long-term educational programs. Source: Author's contribution

the creation of business incubators. Business incubators serve as generators of ideas, where students, together with teachers, embody ideas to create new small enterprises.

Support for the creation of new small enterprises can be provided both through bank lending and by attracting venture capital. Therefore, such approach requires control and supervision by an audit, as well as the provision of reports to the company, which is the guarantor of issued social impact bonds. In this case, social impact bonds will be secured by the material base of business incubators and successfully developed business projects to create new small enterprises. And the source of repayment of social impact bonds will be income from the entrepreneurial activities of created small enterprises, in the development of which the company is interested.

Thus, the paper reveals the conclusion that social impact bonds are based on the logic of modern ideas of sponsorship. This idea states that the effectiveness of grants is often doubtful, and therefore, the real investment programs of social institutions and compensation of invested funds become the driving force for the development of society, if these social programs have achieved the desired results. This approach allows us to solve two main problems of modern charity at once: the first is to attract new participants to active social activities at the expense of a wide range of investors, the second is to increase the quality and effectiveness of social programs implemented, as an investor, who is new source of control over the quality of social programs appears. In addition, SIB financing opens up new opportunities for the development of private and public partnerships in the social sphere, allowing the state to pay only for real social projects and save money to solve other equally important and complex social tasks. Therefore, the use of social impact bonds as an additional source of financing for higher education institutions in modern conditions is a very interesting and attractive tool. 


\section{Conclusion}

As a result of the study, it was concluded that social impact bonds can be used to additionally funding of higher education institutions. This is possible due to the fact that higher education pursues not only the educational and scientific aspect, but also solves the social problems of society, since graduates of higher schools, realizing their knowledge in the process of work, benefit society and the state as a whole, ensuring its constant development.

Social impact bonds can be used along with other sources of financing, such as bank loans, state and municipal funding. Social impact bonds are an extrabudgetary tool and a source of financing for universities and are based on the interaction of many participants: the state, social facilities, banks, non-profit organizations, investors, social auditors, investment consultants and others. The obtained results of the study allowed the development of three innovative approaches to issuing social bond by the universities. The first approach is based on the issuance of social bonds by the bank with the purpose of financing the university. The second approach is based on the issuance of social bonds by university with governmental participation with the purpose of the implementation of the investment program; it presupposes the loan repayment depending on the obtained result. And the third approach is based on the issuance of social bonds with the purpose of financing the long-term educational programs.

Despite the general positive opinion on the use of social impact bonds, the paper indicates that there are obstacles to their use. The main obstacle may be resistance from the public sector, which is mainly due to the lack of experience in publicprivate partnerships. But in the process of developing society, the experience of public-private partnerships will accumulate, and their interaction will become close and inevitable. The research concluded that, in order to accelerate the implementation of universities' social impact bonds in Latvia, it is necessary to launch a pilot project at the municipal level. It should be noted that this study can be continued; further research will focus on comparative analysis of social bond using in higher education institutions in different countries.

\section{References}

Acevedo, J.D.R., \& Live, L.T. (2016). Impact Bonds in the Latin-American Context: Policy Transfer Analysis for Mexico, Chile and Colombia. Conference Paper, 17th Conference: International Scientific Conference on Economic and Social Development, Warsaw, Poland. Accessed Jan 25, 2021, from https://www.researchgate.net/publication/311320308_Impact_ Bonds_in_the_Latin-American_Context_Policy_Transfer_Analysis_for_Mexico_Chile_and_ Colombia

Bloomgarden, D., Eddy, M., \& Levey, I. Z. (2014). Social ımpact bonds and education in Latin America. Accessed Feb 25, 2021, from https://www.instiglio.org/wp-content/uploads/2016/05/ Eddy-et-al-SIBs-in-Education-in-LatAm-GEMS-White_Paper_FINAL.pdf 
Broccardo, E., \& Mazzuca, M. (2019). The missing link? Finance, public services, and co-production: The case of social impact bonds (SIBs). Public Money \& Management., 39(4), 262-270.

Burand, D, (2013). Globalizing Social finance: How social impact bonds and social impact performance guarantees can scale development (pp. 452-465). University of Michigan Law School; Center for Global Development and Social Finance. Accessed Feb 25, 2021, from https://repository.law.umich.edu/articles/1087/

Choudhary, R., \& Jain, V. (2017). Social impact bonds: An innovative way for social financing. Pacific Business Review International., 9(10), 120-126.

Dear, A., Helbitz, A., Khare, R., Lotan, R., Newman, J., Sims, G. C., \& Zaroulis, A. (2016). Social impact bonds: The early years. Social Finance Journal, 5(2), 21-45.

Eddy, M. (2015). Perspectives on impact bonds: The next five years for international development (pp. 325-480). Instiglio.

Gustafsson-Wright, E., Golden, M. \& Aigner-Treworgy, S. (2015a). Identifying education outcomes for social impact bonds for early childhood (215-318). Series Impact Bonds.

Gustafsson-Wright, E., Gardiner, S., \& Putcha, V. (2015b). The potential and limitations of umpact bonds. Lessons from the first five years of experience worldwide. A Landscape of Existing Social Impact Bond Transactions. Common Claims about Impact Bonds (pp. 11-128). Accessed Jan 20, 2021, from https://www.brookings.edu/wp-content/uploads/2016/07/impactbondsweb.pdf

Horesh, R. (2008). Injecting incentives into the solution of social problems: Social policy bonds. Economics Affairs Journal, 6(1), 39-42. https://doi.org/10.1111/1468-0270.00237

Ives, A. (2015). Neoliberalism and the concept of governance: Renewing with an older liberal tradition to legitimate the power of capital. Open Edition Journal., 14(1), 1-15. https://doi.org/ $10.4000 /$ mimmoc. 2263

Jackson, E. T. (2013). Evaluating social impact bonds: Questions, challenges, innovations, and possibilities in measuring outcomes in impact investing. Community Development Journal., 44 (5), 608-616. https://doi.org/10.1080/15575330.2013.854258

Kottmann, A., Vossensteyn, J.J., Kolster, R Veidemane, A., Blasko, Z. Biagi, F., \& SanchezBarrioluengo, M. (2019). Social inclusion policies in higher education: Evidence from the EU. JRC Working Papers. Joint Research Centre. Accessed Feb 12, 2021, from https://ideas. repec.org/p/ipt/iptwpa/jrc117257.html

Laruffa, F. (2018). Social investment: Diffusing ideas for redesigning citizenship after neo-liberalism? Critical Social Policy Journal, 38(4), 688-706. https://doi.org/10.1177/ 0261018317749438

Maier Maier, F., \& Meyer, M. (2017). Social impact bonds and the perils of aligned interests. MDPI, Open Access Journal., 7(3), 1-10.

Marco, A. (2018). A responsibility to profit? Social impact bonds as a form of "humanitarian finance". New Political Science, 40(4), 708-726.

Mulgan, G., Reeder, N., Aylott, M., \& Bosher, L. (2011). Social impact investment: The challenge and opportunity of social tmpact bonds. Accessed Jan 25, 2021, from https://youngfoundation. org/wp-content/uploads/2012/10/Social-Impact-Investment-The-opportunity-and-challenge-ofSocial-Impact-Bonds-March-2011.pdf

Salerno, C. (2016) Higher education: Social impact bonds and income share agreements. Miller Center. University of Virginia. Accessed Feb 10, 2021, from http://web1.millercenter.org/ commissions/higher-ed/Salerno_No8.pdf

Stump, E. K., \& Johnson, A. F. (2016). An examination of using social impact bonds to fund education in Maine in Main. University of Southern Maine. 1 (1), 1-15. Accessed May 20, 2021, from https://core.ac.uk/download/pdf/230396944.pdf

Tan, S., Fraser, A., McHugh, N., \& Warner, M. (2019). Widening perspectives on social impact bonds. Journal of Economic Policy Reform., 27(2), 113-127. https://doi.org/10.1080/ 17487870.2019 .1568249

Warner, M. E. (2013). Private finance for public goods: Social impact bonds. Journal of Economic Policy Reform., 16(4), 303-319. 


\section{On-Line Documents}

Central Statistical Bureau of Latvia. Education. (2021). Higher education institutions and colleges. Accessed Feb 25, 2021, from https://www.csb.gov.lv/en/statistics

Eurostat. (2020). Accessed Apr 15, 2021, from https://ec.europa.eu/eurostat/web/education-andtraining/data/database

Latvian Ministry of Education and Science. (2021). Statistical data. Accessed Feb 25, 2021, from https://www.izm.gov.lv/en

OECD report. (2020). Public and private investment in educational institutions: Education at a Glance. Accessed Feb 12, 2021, from https://www.oecd.org/education/education-at-a-glance/

Natalia Konovalova, $\mathrm{PhD}$ is Associate Professor and Researcher of Economics and Finance Department, RISEBA University of Applied Sciences, Riga, Latvia. She has more than 20 years of academic work experience. She actively participates in international scientific and academic conferences, as well as in the scientific Council and organizing Committee of conferences. She also organizes international scientific and academic conferences in Latvia annually since 2015. She has over 20 publications in scientific journals. She is Editorial Board member in 6 scientific journals, which are publishing in Latvia, Estonia, Macedonia and South Korea. She takes part in different research projects and is Expert of Latvian Scientific Council from 2018. Scientific interests: Social Entrepreneurship, Higher Education, Finance, Banking, Insurance, Risk Management.

Open Access This chapter is licensed under the terms of the Creative Commons Attribution 4.0 International License (http://creativecommons.org/licenses/by/4.0/), which permits use, sharing, adaptation, distribution and reproduction in any medium or format, as long as you give appropriate credit to the original author(s) and the source, provide a link to the Creative Commons license and indicate if changes were made.

The images or other third party material in this chapter are included in the chapter's Creative Commons license, unless indicated otherwise in a credit line to the material. If material is not included in the chapter's Creative Commons license and your intended use is not permitted by statutory regulation or exceeds the permitted use, you will need to obtain permission directly from the copyright holder.

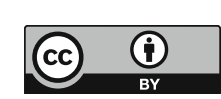

